\title{
The Impact of Job Stress on Deviant Workplace Behavior: The Mediating Role of Job Satisfaction
}

\author{
Marwa Anis, Dina Emil \\ Department of Business Administration, The British University in Egypt, El Shorouk City, Egypt \\ Email: marwa.anis@bue.edu.eg
}

How to cite this paper: Anis, M., \& Emil, D. (2022). The Impact of Job Stress on Deviant Workplace Behavior: The Mediating Role of Job Satisfaction. American Journal of Industrial and Business Management, 12, 123-134.

https://doi.org/10.4236/ajibm.2022.121008

Received: November 11, 2021

Accepted: January 27, 2022

Published: January 30, 2022

Copyright $\odot 2022$ by author(s) and Scientific Research Publishing Inc. This work is licensed under the Creative Commons Attribution International License (CC BY 4.0).

http://creativecommons.org/licenses/by/4.0/

\begin{abstract}
Purpose: The current study's main goal is to investigate the impact of job stress on deviant workplace behavior in Egyptian firms. More precisely, it analyzes common job stresses such as role conflict, work overload, and role ambiguity, as well as non-job-related stressors such as family-to-work conflict. The proposed model is based on general strain theory. Design/Methodology/Approach: Multiple regression analysis is utilized in this study to investigate the relationship between variables, and structural equation modeling is used to assess structural links between measured variables and estimate the significance and size of causal linkages between the variables. Finally, a statistical model's goodness of fit is used to assess and characterize how well a set of observations fits. It summarizes the discrepancy between the observed values and the predicted values under the statistical model. Findings: Results of the study have found that job stress has no direct effect on deviant workplace behavior; however, job satisfaction directs the effect which means that when employees are stressed, their satisfaction may decrease and so their deviant behavior may increase. Research Limitations/Implications: Because of the research approach and sampling technique used, the research findings may be limited in their generalizability. As a result, researchers are encouraged to examine the presented assumptions further. Practical Consequences: The study discusses the implications for the development workplace environment as well as managing the balance of work and family obligations. Originality/Value: This report addresses an acknowledged need by investigating how deviant workplace behavior might be reduced.
\end{abstract}

\section{Keywords}

Deviant Workplace Behavior, Job Satisfaction, Stress Factors, Non-Related Job Stress Factor 


\section{Introduction}

The current paper is developed to illustrate and analyze the impact of job stress on deviant workplace behavior in Egyptian organizations and to identify the stress-related factors that may have a major impact on deviant behavior in the workplace. While stress factors are generally classified into job-related factors and non-job-related factors, yet previous research has focused on the job-related factors when studying the relationship between stress and deviant workplace behavior (e.g. Raza et al., 2017; Silva \& Ranasinghe, 2017; Farhadi et al., 2015; Omar et al., 2011). Even though the relationship between the job-related factors stress and deviant workplace behavior is well documented as mentioned, results in the previous literature are inconsistent. That increases the interest in studying the non-job-related stress factors and especially if it is adopted in different contexts. In addition, there are very few publications that addressed the issue of the impact of job stress on deviant workplace behavior outside the western culture context (Boekhorst, 2015). In spite of the fact that Egypt is considered among the highest countries in terms of encountering factors that cause stress; Egypt has scored the $15^{\text {th }}$ of the most stressful among 74 countries (Bower, 2016), there are very limited studies which considered it as a research context. The importance of the current study comes from the idea that the profound investigation of the main causes of deviant workplace behavior can help in providing managers suggestions to reduce it and this in return, may support the development of organizations. Accordingly, the main purpose of the current study is directed into investigating the impact of job stress on the deviant workplace behavior in Egyptian organizations, to identify the stress-related factors that may have a major impact on deviant behavior in the workplace, and specifically the work-to-family conflict as a non-job-related stress factor on deviant workplace behavior. More specifically, it considers the common factors of job stressors role conflict, work overload and role ambiguity besides the non-job-related stress factors which are the family-to-work conflict. The model suggested is based on the general strain theory.

\section{Literature Review}

Deviant workplace behavior is considered as an individual's voluntary conduct that violates organizational standards; thus, it threatens its members and the welfare of the entire organization (Robinson \& Bennett, 1995). It has been categorized in the literature into two main groups: positive and negative (Alias et al., 2013). Similarly, it is categorized as constructive or destructive deviant behavior (Appelbaum \& Matousek, 2007). Job stress-related factors are work overload, complex tasks, role ambiguity and role conflict (Michie, 2002). 1) Work overload: is the discrepancy between the time limits, resources availability and requirements is associated to tasks work overload (Silva \& Ranasinghe, 2017). Workload is correlated with many sorts of negative and unfavorable outcomes, such as fatigue, tension and anxiety (Ganster \& Rosen, 2013). 2) Role conflict: it is the conflict between the main role for the individual and the pressure exerted on the 
individual by other requests (Kahn, Wolfe, \& Quinn, 1964). 3) Role ambiguity: is lack of clarity about the job tasks and lack of understanding and knowing the job responsibilities and the expectations from one's job performance that tend to lower the performance of the employees (Flaherty, Dahlstrom, \& Skinner, 2013). On the other side the non-job related factors "is an inter role conflict form in which role pressures from the family and work role domains are alternately incompatible because participation in one role is made more difficult by virtue of participation in the other" (Greenhaus \& Beutell, 1985). The work-to-family conflict is one of the common sources of job stress (Solomon 1994; Schaufeli, Nachreiner, \& Bakker, 2001). Many theoretical explanations have examined how job stress in the workplace relates to deviant behavior (Golparver et al., 2015). Previous research studies (Silva \& Ranasinghe, 2017; Radzali, Ahmad, \& Omar, 2013) have based their results on the general strain theory (GST), which attempts to recognize the stresses or strains that could cause deviant behavior (Agnew \& White, 1992). The GST theory argues that stressors or strains raise the likelihood of negative emotions like depression, frustration and anger, so the incidence of deviant behavior is due to these strains. Consequently, these negative emotions create pressure and deviant behavior is one of the ways some people react. Accordingly, the current study proposes the framework (Figure 1) based on the general strain theory to find out the relationship between job stresses and deviant workplace behavior. The literature has not included various types of issues leading to job and resulting deviant behaviors that can be caused by the job stress and which deviant behavior type (production deviance, political deviance, personal aggression and property deviance) was more stressful for the Egyptian organizations. There is a need to observe which type of deviant behavior is riskier for the organization in the presence of stress and depression at workplace (Figure 2).

\section{Methodology}

The participants in this study were 403 employees working in different private Egyptian organizations who were selected by a convenience sampling technique.

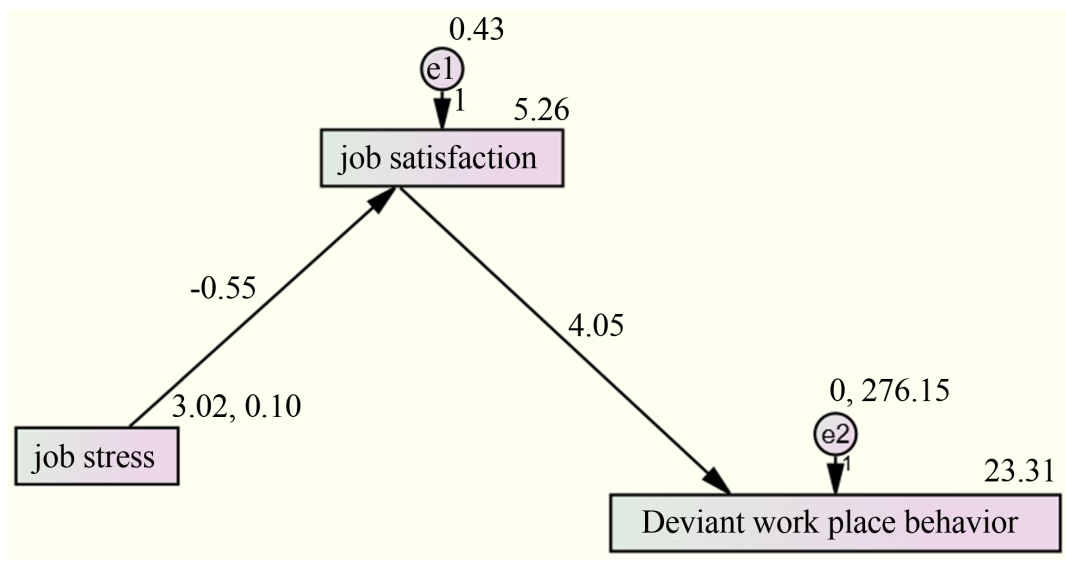

Figure 1. Path analysis. 


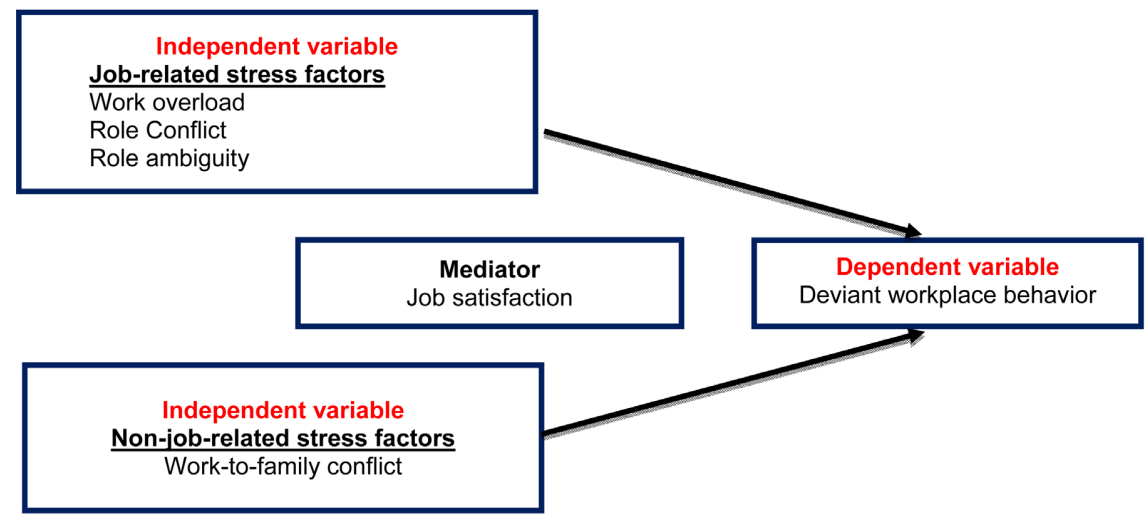

Figure 2. The proposed model.

The study has applied the Cochran Formula to assess the sample size was correct from the selected population size. The Cochran formula is applied on a heterogenous population.

The formula is:

$$
n o=Z^{2} p q / e^{2} .
$$

$e=$ the standard deviation and error that is also known as margin of error.

Data is collected through a structured questionnaire. A pilot study was conducted that enrolled ten participants. After conducting the study, it was found that the questionnaire contained some questions that were inappropriate for the culture so the researcher made changes in the questionnaire by removing some of the questions that did not fit with the culture and rewrote some questions to make them adapted to the culture. In order to check the reliability and the validity of the questionnaire, Cronbach's alpha is used to ensure that the questionnaire obtained relevant data for the study.

The multiple regression analysis, the structural equation modeling technique are used to analyze structural relationships between measured variables. Lastly, the goodness of fit of a statistical model is used to test and describe how well the set of observations fits. It summarizes the contradiction between the values observed and the predictable values under the statistical model (Maydeu-Olivares \& García-Forero, 2010).

\section{Results and Findings}

The survey data described that the majority of the respondents are female as they represent $50.6 \%$ and male represent $49.4 \%$. In terms of age, the majority of respondents are between 31 to 40 years old (36.1\%), respondents between the ages of 20 to 30 represent $34.3 \%, 19.4 \%$ of the respondents represent the ages of 41 to 50 years and $10.2 \%$ of the respondents represent ages above 50 . Regarding the respondents' educational level, the majority of the respondents' educational status is Bachelor's degree. The majority of the respondents work in private organizations (50\%) followed by $31 \%$ working in public organizations and only $19 \%$ working in multinational organizations. As for the workplace, the majority of 
the respondents had worked at their current workplace for more than ten years; the majority of the respondents are working in the educational sector. According to the job role, almost half of the respondents are managers, supervisors and executives and $90 \%$ of respondents work in full-time jobs while only $10 \%$ work part time.

The descriptive analysis results showed that the mean and the standard deviation of the job stress is $(3.0171,0.32)$. This means that there is a tendency for the respondents to neutrally agree for job stress. The majority of the respondents agreed to a great extent that they have an extremely large amount of work to do in their jobs, with a mean of 4.05, their job is difficult and requires a high level of knowledge and technical skill, with a mean of 3.92, they need to always think about their work throughout their working day, with a mean of 3.96 , and they sometimes cannot complete their work in the required time, with a mean of 3.51. However, the respondents were neutral in the extent to which they agreed that their job requires a lot of physical work, with a mean of 3.24, and that their knowledge and skills are rarely used at work, with a mean of 3.23. Respondents agreed that they can reflect their opinions on workplace policy, with a mean of 2.44 , their workplace atmosphere is friendly, with a mean of 2.29 , their jobs do not interfere with their families, social obligations and their social needs with a mean of 2.26, they can choose how and in what order to do their work with a mean of 2.23 and that their jobs suit them well.

The results showed that the mean and the standard deviation of the job satisfaction are $(3.596,0.68)$. This means that there is tendency for the respondents to agree that they are satisfied in their jobs. According to descriptive analysis, results for the dependent variable, the deviant workplace behavior, the mean and the standard deviation of the job satisfaction are $(2.106,0.96)$. This means that there is a tendency for the respondents to disagree for the statements of the deviant workplace behavior, meaning that respondents are less deviant in their workplaces.

Reliability and intrinsic validity for research dimensions: The reliability of the variables was acceptable as all the variables were in the range of 0.7 to 1 which means that the results of the questionnaire are stable. The confirmatory factor analysis showed that all the communalities values for all components are equal to 0.4 or more, which indicate high validity of these items, most of the values of loadings are greater than 0.5 that indicates high correlation between these questions so construct validity for the questionnaire is acceptable.

\subsection{Correlational Analysis}

From the correlation analysis in Table 1, it is clearly shows that, there is a significant negative relationship between job stress and each of job satisfaction, and the deviant workplace behavior. Which means that increasing job stress decrease the satisfaction, and increase the deviant workplace behavior with a confidence level $95 \%$, as $p$-value is less than 0.05 . There is a significant positive relationship between job satisfaction and the deviant workplace behavior, which means that 
Table 1. Correlation analysis.

\begin{tabular}{ccccc}
\hline \multicolumn{5}{c}{ Correlations } \\
\hline & $\begin{array}{c}\text { Job } \\
\text { stress }\end{array}$ & $\begin{array}{c}\text { Job } \\
\text { satisfaction }\end{array}$ & $\begin{array}{c}\text { Deviant } \\
\text { workplace behavior }\end{array}$ \\
\hline \multirow{3}{*}{ Job stress } & Pearson correlation & 1 & $-0.264-^{* *}$ & $-0.123-^{*}$ \\
& Sig. (2-tailed) & & 0.000 & 0.014 \\
& $\mathrm{~N}$ & 399 & 397 & 395 \\
\hline \multirow{3}{*}{ Job satisfaction } & Sig. (2-tailed) & 0.000 & & $0.162^{* *}$ \\
& $\mathrm{~N}$ & 397 & 401 & 0.001 \\
& & & & 398 \\
\hline
\end{tabular}

${ }^{* *}$ : Correlation is significant at the 0.01 level (2-tailed); *: Correlation is significant at the 0.05 level (2-tailed).

increasing job satisfaction decrease the deviant workplace behavior with confidence level $95 \%$, as $p$-value less than 0.05 .

\subsection{Multiple Regression Analysis}

From the regression analysis shown in Table 2, it is concluded that there is significant negative relation between job stress and job satisfaction with a confidence level of $95 \%$ as $p$-value is less than 0.05 . The effect of job stress on job satisfaction equals to -0.553 . There is significant positive relation between job satisfaction and deviant work place behavior with confidence level $95 \%$ as $p$-value is less than 0.05 . This direct effect of job satisfaction on deviant workplace behavior equal 4.055, and indirect effect of job stress on deviant workplace behavior as -2.24 .

Therefore, the job satisfaction mediates the relationship between job stress and deviant workplace behavior with confidence level 95\%.

\subsection{SEM Models}

This Structural equation modeling technique is used to estimate the following relationship between variables:

$$
\begin{gathered}
\text { Job satisfaction }=\beta_{0}+\beta_{1} * \text { job stress } \\
\text { Deviant }=\beta_{0}+\beta_{1} * \text { Job satisfaction }
\end{gathered}
$$

The path analysis graph indicates a negative relationship between job stress and the job satisfaction, which equals to -0.55 and a positive relationship between job satisfaction and deviant workplace behavior, which equals to 4.05 , this method showed the direct effect of the independent variable (Job stress) on the mediator variable (Job satisfaction) and a direct effect of the mediator (Job satisfaction) on the dependent variable (Deviant workplace behavior). The structural modeling equation gives rise to job satisfaction as it is the mediating variable which balances the relationship between job stress and deviant workplace behavior. 
Table 2. Regression analysis.

\begin{tabular}{|c|c|c|c|c|c|c|c|}
\hline & & & Estimate & S.E. & C.R. & $p$ & Label \\
\hline Job satisfaction & $\leftarrow$ & Job stress & -0.553 & 0.102 & -5.432 & $* * *$ & \\
\hline $\begin{array}{c}\text { Deviant } \\
\text { workplace behavior }\end{array}$ & $\leftarrow$ & Job satisfaction & 4.055 & 1.227 & 3.305 & $* * *$ & \\
\hline
\end{tabular}

${ }^{* * *}$ mean that $p$-value less than 0.05 .

\subsection{Regression Analysis}

The analysis in Table 3 shows that there is a significant positive impact of work overload on deviant workplace behavior with confidence level $95 \%$, as $p$-value is less than 0.05 . This means that when the work overload increases, deviant behavior in the workplace increases. On the other hand, there is a significant negative impact of role ambiguity on deviant workplace behavior with confidence level $95 \%$ as $p$-value is less than 0.05 , there is a significant negative impact of role conflict on deviant workplace behavior with confidence level $95 \%$ as $p$-value is less than 0.05 and there is a significant positive impact of work-family conflict on deviant workplace behavior with confidence level $95 \%$ as $p$-value is less than 0.05 .

\subsection{Goodness of Fit}

From Table 4, it is concluded that all the goodness of fit measures of the model indicate that all indicators at acceptable limits, especially NFI, RFI, IFI, TLI, and CFI as they are close to one as the fit index varies from 0 to 1 and 1 is considered ideal. Also, the normed Chi-square with cut-off values is less than 5 and the acceptance criterion ranging from less than 2 to less than 5 (Moss, 2016). The fit measures indicate the goodness of fit of the structural model and its ability to measure the mediation effect of job satisfaction on the relationship between job stresses on deviant workplace behavior.

\section{Discussion}

The study shows that there is a significant negative relationship between job stress and job satisfaction as when employees are stressed in their workplace, they became dissatisfied. This finding is consistent with previous research findings carried out by Hoboubi et al. (2016), Venkataraman \& Ganapathi (2013), Bemana et al. (2013) as they concluded in their studies that there is a negative significant relationship between the job stress and the job satisfaction.

Additionally, there is a significant positive relationship between job dissatisfaction and deviant workplace behavior which means that when job satisfaction decreases, deviant workplace behavior increases. This finding is consistent with previous research findings as a study conducted on white- and blue-collar employees found that the reason for production deviance, theft and sabotage is dissatisfaction and the dissatisfaction is due to abusive supervision (Anjum \& Parvez, 2013). This is also supported by previous literature, which reports that employees 
Table 3. Regression analysis (stress factors).

\begin{tabular}{lcccccc}
\hline & & & Estimate & S.E. & C.R. & $p$ \\
\hline Deviant workplace behavior & $\leftarrow$ & Work overload & 0.266 & 0.089 & 2.99 & 0.003 \\
Deviant workplace behavior & $\leftarrow$ & Role ambiguity & -0.469 & 0.051 & -9.23 & $* * *$ \\
Deviant workplace behavior & $\leftarrow$ & Role conflict & -0.185 & 0.043 & -4.33 & $* * *$ \\
Deviant workplace behavior & $\leftarrow$ & $\begin{array}{c}\text { Work to } \\
\text { family conflict }\end{array}$ & 0.201 & 0.038 & 5.24 & $* * *$ \\
\hline
\end{tabular}

Table 4. Goodness of fit table.

\begin{tabular}{cc}
\hline The goodness of fit Indices for the estimated SEM \\
\hline Chi-square & 4.005 \\
Degree of freedom & 6 \\
Level of significance & 0.000 \\
Normed chi-square & 2.916 \\
Normed fit index (NFI) & 0.931 \\
Relative fit index (RFI) & 0.983 \\
Incremental fit index (IFI) & 0.953 \\
Relative fit index (TLI) & 0.981 \\
Comparative fit index (CFI) & 0.947 \\
\hline
\end{tabular}

who are highly satisfied with their jobs are more likely to stay committed to the regulations and norms set by their organization and are less likely to engage in deviant behavior in the workplace (Sims, 2002).

Thus, the current study findings showed that there is an indirect effect between job stress and deviant workplace behavior but the effect of job satisfaction is mediating the relation between job stress and deviant workplace behavior. However, it shows an inconsistency with previous theoretical explanations and empirical findings, which show a significant positive relationship and direct effect of job stress on deviant workplace behavior (e.g., Omar et al., 2011; Silva \& Ranasinghe, 2017).

The study found that there is a positive impact of work overload on deviant workplace behavior as when workload increases, employees are more likely to engage in deviant behavior in the workplace. The study results are consistent with other researchers' findings (Norsilan, Omar, \& Ahmad, 2014; Silva \& Ranasinghe, 2017) as they also found that work overload has a significant impact on the deviant workplace behavior and that job demand pressure cause employee to involve in many forms of deviant behavior in the workplace.

The work overload occurs when employees have tasks with heavy responsibilities; employees need high effort to accomplish the work demands and work demands are beyond the employee capabilities (Bateman, 1981). Therefore, these is- 
sues will make employees feel stressed and depressed which will lead them to behave negatively in their workplaces. On the other hand, the findings were quite unexpected in that there is a significant negative impact of role ambiguity and role conflict on deviant workplace behavior. This is inconsistent with the previous literature which shows a positive and significant relationship between role conflict and deviant workplace behavior (Hussain et al., 2017) and other studies that show that role ambiguity has an insignificant impact on deviant workplace behavior (Silva \& Ranasinghe, 2017). Job satisfaction is the reason behind this relationship as even when employees face difficulties in their workplace but they are supported and satisfied, they will not engage in any deviant behavior. So even when there is conflict and ambiguity in the employees' role but they are satisfied, deviant workplace behavior will decrease.

The result found that role ambiguity and role conflict have a positive impact on the deviant workplace behavior. This is supported by the affective events theory, which states that behavior in the workplace is guided by the feelings and emotions of the employees so employees can involve in deviant behavior when they feel negatively in their workplace (Weiss, Cropanzano, \& Russell, 1996). However, the mediation effect of job satisfaction can make positive feelings and emotions that will make employees satisfied and their deviant behavior will decrease.

Regarding the non-job related stress factors; there is a positive significant impact of the work to family conflict on the deviant workplace behavior, as employees who suffer from conflict between their job role and their family role are more likely to engage in deviant behavior in the workplace. This result is in good agreement with other studies as referred to the literature review (Darrat, Amyx, \& Bennett, 2010; Rubab, 2017; Radzali, Ahmad, \& Omar, 2013).

Workers who suffer from work-to-family conflict could be more prone to engage in production deviance as the pressure of this conflict drains the workers' concentration and energy, which are required in the work so they will be less productive in their workplace. Furthermore, workers that are incapable of meeting their family expectations due to time pressure may leave work early to accomplish their family responsibilities, rushing through their tasks which lead to them producing low-quality work.

\section{Limitations of the Study and Suggestions for Future Research}

The data collection relied merely on primary data by using a structured questionnaire that indicates that some respondents might not be able to provide more elaboration about some important facts. The sample is based only the private sectors; therefore, the conclusion and the finding may not be generalized. Also, the drawbacks of the convenience sampling technique are that it indicates the limited access to respondent, so it is expected that different sample of respondents may provide different results. For further research, it is recommended 
to include qualitative data through individual interviews to interact directly with employees. In addition, it is recommended to improve the sampling techniques to have more representative sample that will enable better generalization of results.

\section{Conclusion}

The main purpose of this study is to investigate the impact of job stress on deviant workplace behavior in Egyptian organizations. Results of the study have found that job stress has no direct effect on deviant workplace behavior; however, job satisfaction directs the effect which means that when employees are stressed, their satisfaction may decrease and so their deviant behavior may increase. On the other side, the stress in the workplace is expected to decrease when the employees are overall satisfied with their organization as when they are satisfied with their organization culture. So when employees' satisfaction increases, they will be less likely to involve in deviant behaviors.

The study has found that job satisfaction plays a crucial role in decreasing deviant workplace behavior. Accordingly, when employees are stressed, this may increase their satisfaction level, so they will be more likely to involve in deviant behavior and when employees are less stressed, they will be satisfied so they will be less likely to involve in deviant behavior. Further, it has been demonstrated that the major stress factors that are likely to push employees to deviant behavior are work overload and this is a job related stress factor; the work to family conflict as a non-related job stress factor. The findings clearly showed that there is a significant positive impact of work overload on deviant workplace behavior which means employees who suffer from work overload and pressure in their jobs, such as having too much work to do are more likely to engage in deviant behavior.

Regarding the work-family conflict, results showed that it has a significant positive impact on deviant workplace behavior such as when employees face struggles and conflicts in the balance between their jobs requirement and their family roles, they will tend to engage more in deviant behavior such as failure to abide by the working hours and their absenteeism in order to be able to contribute to their family roles. Thus, their work product will decrease.

To sum up the results, it can be concluded that job satisfaction plays a crucial role as it can decrease or even eliminate deviant behavior in the workplace, thus a less stressed workplace will increase employees' satisfaction and help decrease their deviant behavior.

The current study's advantage is its generalizations that can be implemented in the wider populations. This is due to the involvement of job stress and depression that can create trouble of deviance at any workplace.

\section{Conflicts of Interest}

The authors declare no conflicts of interest regarding the publication of this paper. 


\section{References}

Agnew, R., \& White, H. R. (1992). An Empirical Test of General Strain Theory. Criminology, 30, 475-500. https://doi.org/10.1111/j.1745-9125.1992.tb01113.x

Anjum, M. A., \& Parvez, A. (2013). Counterproductive Behavior at Work: A Comparison of Blue Collar and White Collar Workers. Pakistan Journal of Commerce and Social Sciences, 7, 417-434.

Appelbaum, S. H., Iaconi, G. D., \& Matousek, A. (2007). Positive and Negative Deviant Workplace Behaviors: Causes, Impacts, and Solutions Corporate Governance, 7, 586-598. https://doi.org/10.1108/14720700710827176

Bateman, T. S. (1981). Work Overload. Business Horizons, 24, 23-27. https://doi.org/10.1016/S0007-6813(81)80022-5

Bemana, S., Moradi, H., Ghasemi, M., Taghavi, S. M., \& Ghayoor, A. H. (2013). The Relationship among Job Stress and Job Satisfaction in Municipality Personnel in Iran. World Applied Sciences Journal, 22, 233-238.

Boekhorst, J. A. (2015). Human Resource Management Practices, Work Intensity, and Workplace Deviance: Exploring the Moderating Role of Core Self-Evaluations. Toronto: York University.

Bower, E. (2016). The Growing Problem of Stress in the Workplace. American Chamber of Commerce in Egypt.

https://www.amcham.org.eg/publications/business-monthly/issues/250/October-2016/ 3502/the-growing-problem-of-stress-in-the-workplace

Darrat, M., Amyx, D., \& Bennett, R. (2010). An Investigation into the Effects of WorkFamily Conflict and Job Satisfaction on Salesperson Deviance. Journal of Personal Selling \& Sales Management, 30, 239-251. https://doi.org/10.2753/PSS0885-3134300304

Farhadi, H., Nasir, R., Omar, F., \& Nouri, A. (2015). Understanding Employees' Deviant Behaviour: The Role of Agreeableness and Stress Related to Work. Journal of Social Sciences and Humanities, 102-107.

Flaherty, T. B., Dahlstrom, R., \& Skinner, S. J. (2013). Organizational Values and Role Stress as Determinants of Customer-Oriented Selling Performance. Journal of Personal Selling \& Sales Management, 19, 1-18.

Ganster, D. C., \& Rosen, C. C. (2013). Work Stress and Employee Health: A Multidisciplinary Review. Journal of Management.

Golparver, M., Taleb, M., Abdoli, F., \& Abedini, H. (2015). Stress Coping Styles Moderating the Relationship between Job Stress and Deviant Workplace Behaviors: Some Gender Discriminations. American Journal of Economics, Finance and Management, 1, 377 387.

Greenhaus, J. H., \& Beutell, N. J. (1985). Sources of Conflict between Work and Family Roles. The Academy of Management Review, 10, 76-88. https://doi.org/10.2307/258214

Hoboubi, N., Choobineh, A., Keshavarzi, S., Hosseini, A. A., \& Ghanavati, F. K. (2016). The Impact of Job Stress and Job Satisfaction on Workforce Productivity in an Iranian Petrochemical Industry. Safety and Health at Work, 8, 67-71. https://doi.org/10.1016/j.shaw.2016.07.002

Kahn, R. L., Wolfe, D. M., \& Quinn, R. P. (1964). Organizational Stress: Studies in Role Conflict and Ambiguity. New York: Wiley.

Maydeu-Olivares, A., \& García-Forero, C. (2010). Goodness-of-Fit Testing. International Encyclopedia of Education, 7, 190-196.

https://doi.org/10.1016/B978-0-08-044894-7.01333-6 
Michie, S. (2002). Causes and Management of Stress at Work. Occupational \& Environmental Medicine, 59, 67-72. https://doi.org/10.1136/oem.59.1.67

Moss, S. (2016). Fit Indices for Structural Equation Modeling. Sico Tests. https://www.sicotests.com/psyarticle.asp?id=277

Norsilan, I. N., Omar, Z., \& Ahmad, A. (2014). Workplace Deviant Behavior: Does Employee Psychological Job Demand and Lack of Job Resources Influence Employee Workplace Deviant Behavior? Jurnal Psikologi Malaysia, 28, 39-62.

Omar, F., Halim, F. W., Zamani, Z. A., Farhadi, H., Nasir, R., \& Khairudin, R. (2011). Stress and Job Satisfaction as Antecedents of Workplace Deviant Behavior. World Applied Sciences Journal, 12, 45-51.

Radzali, F. M., Ahmad, A., \& Omar, Z. (2013). Workload, Job Stress, Family-to-Work Conflict and Deviant Workplace Behavior. International Journal of Academic Research in Business and Social Sciences, 3, 109-115.

Raza, S., Hussain, M. S., Azeem, M., \& Aziz, K. (2017). Workload, Work Stress, Role Conflict, and Workplace Deviant Behaviour in Banks: An Empirical Analysis. European Online Journal of Natural and Social Sciences, 6, 701-707.

Robinson, S. L., \& Bennett, R. J. (1995). A Typology of Deviant Workplace Behaviors: A Multidimensional Scaling Study. The Academy of Management Journal, 38, 555-572.

Rubab, U. (2017). Impact of Work Family Conflict on Burnout and Workplace Deviant Behavior: Mediating Role of Stress. Jinnah Business Review, 5, 1-10.

Schaufeli, W. B., Nachreiner, F., \& Bakker, A. B. (2001). The Job Demand-Resources Model of Burnout. Journal of Applied Psychology, 86, 499-512.

Silva, H. M., \& Ranasinghe, R. M. (2017). The Impact of Job Stress on Deviant Workplace Behavior: A Study of Operational Level Employees of Comfort Apparel Solutions Company in Sri Lanka. International Journal of Human Resource Studies, 7, 74-85.

Sims, R. R. (2002). Managing Organizational Behavior. Praeger.

Solomon, C. (1994). Work Family's Failing Grade: Why Today's Initiative Aren't Enough. Personnel Journal, 73, 72-87.

Venkataraman, P. S., \& Ganapathi, R. (2013). A Study of Job Stress on Job Satisfaction among the Employees of Small Scale Industries. IOSR Journal of Business and Management, 13, 18-22.

Weiss, H. M., \& Cropanzano, R. (1996). Affective Events Theory: A Theoretical Discussion of the Structure, Causes and Consequences of Affective Experiences at Work. In B. M. Staw, \& L. L. Cummings (Eds.), Research in Organizational Behavior: An Annual Series of Analytical Essays and Critical Reviews (pp. 1-74). Greenwich, CT: JAI Press. 